\title{
Effect of herbal biostimulators on rumen liquor, blood and milk constituents of lactating cows
}

\author{
CS Randhawa ', SS Randhawa 1, OS Parmar 2, DC Nauriyal 1 \\ 'Dept Vet Med, PAU Ludhiana ; 2Dept Anim Sci, PAU Ludhiana, 141004 Punjab, India
}

To overcome the problem of low digestibility and reduced milk yield in ruminants, various drugs, hormones, chemical stimulants, minerals, vitamins and feed additives have been used. However, many of these preparations are not economically efficient and also have side effects and are thus harmful to animal and human health. The present study was designed to evaluate the effect of herbal feed additives on rumen fermentation, blood biochemical and milk constituents in lactating dairy cows.

The experiment was conducted in 24 lactating cows which were randomly divided into four comparable groups of six. The animals in control group (C) were provided feed daily without herbal additive. However, in other three groups, $T_{1}, T_{2}$ and $T_{3}$, three herbal feed additives (M/s Indian Herbs, Saharanpur, UP, India) viz., Himalyan Batisa strong $10 \mathrm{~g}$, galog $50 \mathrm{~g}$ and livol $50 \mathrm{~g}$ were fed daily at the time of milking for 42 consecutive days. Animals of each group were provided daily with ad lib feeding of green fodder (leguminous cropberseem) mixed with wheat straw and $4 \mathrm{~kg}$ of concentrate ration (mixture of groundnut / mustard cake + wheat grain + wheat bran + mineral mixture).

Ruminal fermentative activity was assessed by recording sedimentation activity time (SAT), glucose fermentation test (GFT) and methylene blue reduction time (MBRT) as presented by Rosenberger (1979, Clin Exam Cattle, Verlag Paul Parey, Hamburg). Total protozoal count of rumen liquor was determined by the method of Naga and El-Shazly (1969, J Dairy Res, 36, 110). Plasma enzymes ALT, AST and GGT, plasma urea nitrogen and creatine were analysed by using Autopak, Ames reagent kits with the help of Beckman Clinical Analyser (USA). Milk constituents viz. fat, lactose, proteins, total solids and solids not fat were estimated with automated milkoscan.

The orat feeding of three herbal feed additives markedly increased the ruminal fermentative activity reflected by significant $(P \leq 0.05)$ decrease in SAT (mean values $C-10.38 \pm 0.42, T_{1}-5.12 \pm 0.65$, $T_{2}-7.56 \pm 0.76$ and $T_{3}-7.02 \pm 0.73$ minutes) and MBRT ( $C-3.83 \pm 0.21, T_{1}-2.06 \pm 0.32$, $\mathrm{T}_{2}-2.49 \pm 0.38$ and $\mathrm{T}_{3}-2.28 \pm 0.23$ minutes) and increase in GFT $(C-2.56 \pm 0.24$, $T_{1}-3.93 \pm 0.35, T_{2}-3.80 \pm 0.31$ and $\mathrm{T}_{3}-3.82 \pm 0.27 \mathrm{ml} / \mathrm{h}$ ) and total protozoal counts (C - $5.69 \pm 0.18, T_{1}-7.98 \pm 0.27$, $T_{2}-6.77 \pm 0.34$ and $T_{3}-6.92 \pm 0.39 \times 105 / \mathrm{ml}$ ). These effects were most pronounced in $T_{1}$ - followed by $T_{3}$ - and $T_{2}$ - group. There was significant increase in milk yield in the three treatment groups even though all the milk constituents and electrical conductivity of milk showed non-significant fluctuations. Increase in milk yield was maximal in $T_{2}(11.72 \pm 0.64$ $\mathrm{kg} /$ day), followed by $T_{1}(10.93 \pm 0.61 \mathrm{~kg} /$ day $)$, and $T_{3}(10.76 \pm 0.59 \mathrm{~kg} /$ day $)$ groups as compared to that of $C$ group $(8.51 \pm 0.48$ $\mathrm{kg} /$ day). The plasma biochemical constituents viz., AST, ALT, GGT, urea nitrogen and creatine revealed non-significant fluctuations in all the three groups, which reflected that herbal additives were not having any undesirable effect on hepatic and renal functions.

It was inferred that positive effects were attributable to improvement in ruminal fermentation, as well as galactopoietic activity of many of the herbal constituents of these biostimulators which were also unharmful to animal health. 